\title{
REFLEXIONES SOBRE EL GÉNERO MUSICAL EN EL LARGOMETRAJE VASCO DE ANIMACIÓN
}

\author{
Maitane Junguitu Dronda \\ Investigadora independiente
}

\section{Resumen}

Desde que The Walt Disney decide llevar a cabo su primer largometraje de animación tiene muy clara la importancia de la música en sus producciones. El hecho de que otras compañías imiten esas características lleva a considerar el género cinematográfico del «musical animado» como una entidad propia. En el presente artículo presentamos el concepto del musical de animación y luego realizamos una introducción a ejemplos de largometrajes producidos en el Estado español. Después, y basándonos en las teorías de Alba Montoya Rubio (2017), presentamos un análisis global del uso de la música en los largometrajes vascos. Luego realizamos un estudio de las películas Karramarro Uhartea (Josean Muñoz \& Txabi Basterretxea, 2000), La Leyenda del Unicornio (Maite Ruiz de Austri, 2001) y Barriola, San Adriango Azeria (Juanba Berasategi, 2008). Finalmente exponemos conclusiones relativas a la presencia del género musical en el largometraje de animación vasco.

Palabras clave: ANIMACIÓN; CINE VASCO; LARGOMETRAJES; MUSICAL

\section{GENERAL CONSIDERATIONS ABOUT THE MUSICAL FILM GENRE WITHIN THE ANIMATED BASQUE FEATURES}

\section{Abstract}

The Walt Disney Company always considered music important in their works. They first animated feature film was indeed a musical film. Other companies imitate those features. Nowadays we can consider the "animated musical film» as a cinematographic genre. This text explains the characteristics of the animated musical film. Then, we introduce some example of Spanish films. After that we apply the theories of Alba Montoya Rubio (2017) on the Basque Cinematography. We analyze three specific films: Karramarro Uhartea (Josean Muñoz \& Txabi Basterretxea, 2000), La Leyend del Unicornio (Maite Ruiz de Austri, 2001) and Barriola, San Adriango Azeria (Juanba Berasategi, 2008). Finally, we present some conclusions about the musical genre within the Basque animated features.

Keywords: ANIMATION; BASQUE CINEMA; FEATURE FILMS; MUSICAL

\footnotetext{
Junguitu Dronda, Maitane. 2021. "Reflexiones sobre el género musical en el largometraje vasco de animación". AusArt 9 (1): 245-259. D0I: 10.1387 /ausart.22665
}

\section{AUSART}




\section{INTRODUCCIÓN}

La bibliografía referente a la cinematografía vasca destaca por la escasa presencia del cine de animación. Sin embargo, está comprobado que desde mediados de los ochenta en el País Vasco se estrenan varias docenas de largometrajes comerciales de animación. Tal y como defendimos en la tesis doctoral Kalabaza Planeta eta Juanba Berasategi: Panorámica de la animación comercial vasca (Junguitu Dronda 2019), estas películas y sus características son desconocidas no solo entre el público, sino también en el ámbito académico, lo que explica la citada ausencia en la bibliografía.

Partiendo de esa realidad es conveniente desarrollar investigaciones que ayuden a difundir estas obras y analizarlas desde diferentes puntos de vista. En este caso, teniendo en cuenta la relevancia del musical como género cinematográfico dentro del cine de animación, se propone una reflexión sobre el mismo tomando como objeto de estudio los mencionados largometrajes de animación producidos en el País Vasco.

De esta manera, el presente artículo comienza contextualizando el género musical dentro del cine de animación. Acto seguido se revisan los musicales de animación realizados en el Estado español. Seguido, se enumeran, en general, las características de la música utilizada en el cine de animación vasco. Finalmente, se analizan en profundidad tres filmes que destacan por la relevancia de su música: Karramarro Uhartea (Josean Muñoz \& Txabi Basterretxea, 2000), La Leyenda del Unicornio (Maite Ruiz de Austri, 2001) y Barriola, San Adriango Azeria (Juanba Berasategi, 2008)1.

\section{EL MUSICAL ANIMADO COMO GÉNERO CINEMATOGRÁFICO}

La música está ligada al cine desde la invención de la tecnología cinematográfica. La interpretación de música en directo da pie a incorporar la banda sonora junto a las imágenes cinematográficas. Casi al mismo tiempo surge el género cinematográfico musical que cuenta con canciones y coreografías como recurso narrativo característico. Desde que The Walt Disney Company incorpora el sonido a sus obras a finales de la década de los veinte, la música 
adquiere especial relevancia en todos sus trabajos. El característico uso de la música comienza en el cortometraje Steamboat Willie (Walt Disney, Ub Iwerks, 1928), sigue en las Silly Symphonies (1939-1939) y se completa en el estreno de su primer largometraje Snow White and the Seven Dwarfs (David Hand, 1937). Ya durante el trabajo de preparación de Snow White, el propio Walt Disney expresa el cuidado con el que se deben preparar la música y las canciones de las películas. Según Disney, una canción debe de estar siempre justificada dentro de la diégesis, enfatizando que debe aportar algo a la trama y no estar simplemente colocada con objetivos estéticos (Thomas \& Disney 1968).

Después de Snow White siguen más largometrajes que repiten esas estructuras narrativas fundamentadas en las canciones con letra y actos musicales. El éxito de las mismas y la repetición de esas fórmulas por los estudios de la competencia hace que a día de hoy podamos plantear como subgénero el 'musical de animación'.

El musical de animación y las canciones de los largometrajes de The Walt Disney Company son ampliamente estudiados por Alba Montoya Rubio. La autora defiende en su tesis doctoral que no solo se pueden diferenciar etapas respecto al uso de la música en los largometrajes de The Walt Disney Company, sino que también existen funciones específicas en las canciones (Montoya Rubio 2017b). Inicialmente presenta una categorización que determina siete tipos: canciones monólogo, diálogo, lista, narrativa, expositiva, descriptiva y comparativa. Sin embargo, plantea que estas categorías no son lo suficientemente concretas y expone una segunda categorización más completa que tiene en cuenta el argumento, letra, imagen y música de las canciones determinando doce funciones: canción introductoria, de personaje (protagonista o antagonista), de espectáculo, de amor (romántico o maternal), didáctica, de amistad, de trabajo, de esperanza, de carpe diem, de magia, canciones esporádicas -donde se incluyen varias subcategorías como la canción de viaje, surrealista o de despedida $-\mathrm{y}$ conclusivas.

Aunque Alba Montoya Rubio desarrolla los tipos de musicales en su tesis doctoral, queremos subrayar la aportación paralela que hace en un artículo (Montoya Rubio 2017a) en el que diferencia tres principales tipos:

a. El musical puro o «estilo Broadway»: los números musicales son diegéticos -al menos la voz-, hay interpelaciones a cámara y los personajes expresan sus sentimientos. 
b. El «estilo videoclip»: predominan las canciones en over $r^{2}$ que tienen sentido fuera de la película, cantadas por personajes -diegéticas interior-o narradores -extradiegéticas-. En este caso, en ocasiones se pueden encontrar contrastes entre las canciones de la película y la música de fondo. Son ocasionalmente utilizadas para mostrar saltos en el tiempo.

c. Una versión mixta de las dos anteriores.

\section{EL MUSICAL DE ANIMACIÓN EN EL ESTADO ESPAÑOL}

En España el género musical está presente desde que existe el cine sonoro. De hecho, en la primera etapa del cine sonoro el género musical es el segundo con más producciones, destacando las adaptaciones de zarzuelas (Gubern et al. 2017). A lo largo de los años el género va presentando variaciones como el 'cine folclórico' protagonizado por tonadilleras, los niños y niñas cantoras de los años cincuenta o el musical de los ochenta.

Los largometrajes de animación producidos en España también tienen ejemplos de películas musicales. Sin embargo, parece no haber un consenso entre la academia, la prensa y las promociones de los largometrajes respecto a cuál es el primer largometraje de género musical de animación estrenado en España.

María Luisa Martínez Barnuevo en su disertación sobre los largometrajes estrenados entre 1997 y 2007 hace un pequeño inciso sobre este: "En algunas notas de prensa se la consideraba el primer musical del cine de animación español, dato que es erróneo, pues anteriores a La Leyenda del unicornio son La Isla de Cangrejo o Sueños de Tay-Pi" (2008). Los sueños de Tay-Pi (Franz Winsterstein \& José María Blay, 1951) es estrenada en 1951 mientras que Karramarro uhartea y La Leyenda del Unicornio son mucho más recientes. No obstante, si analizamos el primer largometraje de animación producido en España, Garbancito de la Mancha (José María Blay, 1945), se concluye que sus creadores dedican especial atención a la creación de una banda sonora en la que las canciones tienen un valor narrativo similar al de las películas que en los años treinta y cuarenta estrena The Walt Disney Company. 
La banda sonora de Garbancito de la Mancha es compuesta por Jacinto Guerrero con aportaciones de Joaquín Bisbe y es ampliamente estudiada por María José Ramos (Ramos 2012). Por su parte, José María Candel señala que el productor del film tiene dudas sobre el compositor elegido, ya que la música de zarzuela parece lejana a lo que se espera de una película infantil (Candel 1993). Esta película cuenta con varias canciones, interpretadas por voces en over masculinas y femeninas, además de otras cantadas por personajes dentro de la diégesis. Incluso muestra puestas en escena de canciones que recuerdan a las Silly Symphonies de Disney, como sucede con la canción Los Chopos. Los siguientes largometrajes también cuentan con un cuidado uso de la música. Érase una vez... (Alexandre Cirici-Pellicer, 1950) presenta interesantes coreografías musicales y su banda sonora es interpretada por la Orquesta Sinfónica de Radio Nacional de España y varios conjuntos vocales y solistas. Sobre la ya mencionada Los sueños de Tay-Pi, las fuentes de la época apuntan a que muestra una gran cantidad de números musicales compuestos por Augusto Algueró y Arthur Kaps, con la participación de la Capilla Clásica de Mallorca entre otros. Un ejemplo de los años ochenta es Los viajes de Gulliver (Cruz Delgado, 1983), que incluye números musicales cantados por el protagonista de la película.

\section{LA MÚSICA EN LOS LARGOMETRAJES DE ANIMACIÓN VASCOS}

Constatado que la música y el género musical es relevante tanto a nivel internacional como en las producciones españolas, es momento de cerrar el objeto de estudio y dirigir la mirada a los largometrajes de animación producidos en el País Vasco. Para ello tomamos como basé la categorización de las canciones propuesta por Alba Montoya Rubio.

Kalabaza Tripontzia (Juanba Berasategi, 1985) es el primer largometraje vasco de animación y cuenta con una banda sonora compuesta por el grupo de folk vasco Oskorri. La música se limita a acompañar las imágenes y solamente hay una canción de estilo videoclip -cantada por el demonio Galtzagorri-con letra que además rompe con el estilo musical del resto de la película, ya que se trata de una canción rock que ambienta la única historia que se desarrolla en el presente. El segundo largometraje de animación producido en el País 
Vasco, Ipar Haizearen Erronka (Juanba Berasategi, 1992) no presenta ninguna actuación musical ni canción con letra.

La tendencia en los largometrajes vascos es la determinada en esas dos películas: predominan las bandas sonoras que acompañan a la historia, la mayoría de las veces con música orquestada interpretada por agrupaciones incluso de países extranjeros. Junto a eso, ocasionalmente se incluyen canciones extradiegéticas con letra, destacando sobre todo en los créditos iniciales y/o finales y como canciones conclusivas.

Existen varios casos de canciones over para acompañar la narración con letras descriptivas de situaciones o sensaciones que viven los personajes principales. En Olentzero eta Gabonetako Ipuina (Juanjo Elordi, 2002) un narrador canta en primera persona en over-posiblemente el protagonista Anje- la canción Jauzika que le acompaña en su camino.

Cuando se trata de los créditos iniciales las canciones introducen la trama, como en Herensugeak: Haritzaren Bihotza (Ángel Izquierdo \& Ricardo Ramón, 2012) donde se describe el Valle del Dragón. Ejemplo de créditos finales es Blackie\&Kanuto (Francis Nielsen, 2012) a través de la canción No dejes de soñar o Elkano, Lehen Mundu bira (Ángel Alonso, 2019) con Confía en el Viento interpretada por la banda La Oreja de Van Gogh. Glup (Aitor Arregi \& Iñigo Berasategi, 2003) presenta canciones con letra tanto en los créditos iniciales como los finales, en ambos casos interpretados por Ainhoa Cantalapiedra, ganadora en 2002 del concurso televisivo Operación Triunfo.

Las canciones rara vez son cantadas por los protagonistas, siendo uno de los pocos ejemplos la canción over de la protagonista de Glup, utilizada como recurso narrativo para acompañar su regreso a casa o la actuación de estilo Broadway del antagonista de Ametsen Lapurra (Ángel Alonso, 1999).

Observamos varios casos en los que se da un gran acto musical final de función conclusiva como en Betizu eta Urrezko Zintzarria (Egoitz Rodríguez, 2007), que también incluye una canción en over sobre la amistad. En el caso de Pailazokeriak (Imanol Zinkunegi, 2005) los protagonistas Txirri, Mirri y Txiribiton ${ }^{3}$ cantan para su público dos de sus canciones al inicio y al final de la película.

Por otro lado, son varios casos en los que la trama está directamente ligada a la música. En Betizu izarren artean ${ }^{4}$ (Egoitz Rodríguez, 2003) las vacas prota- 
gonistas son miembros de un grupo musical y por lo tanto se las ve actuando en numerosas ocasiones. En esta película encontramos una canción monólogo de esperanza y otra de personaje de estilo videoclip en la que Betisuis reflexiona sobre la fama. Gartxot, Konkista, Aitzineko Konkista (Juanjo Elordi \& Asisko Urmeneta, 2011) presenta varias canciones dentro de la diégesis, muchas de ellas ligadas a la libertad, ya que el protagonista, Gartxot, es un bardo navarro del siglo XII cuyo hijo Mikelot es secuestrado por el abad de Roncesvalles para que cante para el monasterio. Otro ejemplo son los villancicos de las películas de la saga Olentzero, introducidas en la diégesis por los personajes que los cantan. Como ejemplo excepcional debemos mencionar la película para adultos está Black is beltza (Fermin Muguruza, 2018), dirigida por el músico Fermin Muguruza, un proyecto transmedia que conlleva la creación de varios discos además de la banda sonora musical del film.

Entre todos los largometrajes que forman el grueso de la cinematografía de animación del País Vasco hay tres especialmente relevantes por el uso que hacen de la música y por ello creemos relevante analizarlos: Karramarro Uhartea, La Leyenda del Unicornio y Barriola San Adriango Azeria.

\section{KARRAMARRO UHARTEA: LOS PIRATAS CANTORES}

Karramarro Uhartea se estrena en el año 2000 y gana el Goya al mejor largometraje de animación en la edición XV de los galardones. Irusoin es la principal productora pero varios miembros de Lotura Films participan en la misma, incluido Juanba Berasategi que ejerce de montador.

María Luisa Martínez Barnuevo (2008) indica que la película es un musical. Sin embargo, solo cuenta con tres canciones con letra, un tercio de las que aparecen en La Leyenda del Unicornio. La cuidada banda sonora musical está compuesta por Ángel Illarramendi. Illarramendi es un destacado compositor vasco con amplia experiencia en el cine; antes y después de Karramarro Uhartea trabaja en varias películas de imagen real y en una que combina imagen real y animación, El Rey de la Granja (Gregorio Muro \& Carlos Zabala, 2002), pero que no presenta canciones con letra. Los letristas de las canciones de Karramarro Uhartea son los guionistas del film Inazio Mujika y Joxean Muñoz, 
que escriben las letras en euskera una vez Illarramendi compone el esbozo de la música y con la película ya en producción.

Las voces masculinas son interpretadas por el grupo donostiarra Golden Apple Quartet, que más tarde repite en la interpretación de las canciones de la versión española de Toy Story II (Jonh Lasseter, 1999). Las voces femeninas son las de las cantantes Maite Arruabarrena y Amaia Zubiria. La música es interpretada por la Orquesta Sinfónica de Praga.

Estamos ante una película en la que los actos musicales forman parte de la trama, ya que la historia narrada se estructura bajo la premisa de que 'para ser un buen pirata, hace falta saber cantar bien'. La banda sonora está formada por doce canciones de la cuales como hemos adelantado tres tienen letra: Piraten Koplak, Perla Zuria e Itsas Andere, en castellano respectivamente Canción de Caín, Una canción en la Tormenta y Mar de Esmeralda. En todo momento las canciones son parte de la diégesis, es decir, son cantadas por los personajes y pertenecen al estilo Broadway. Además, en el caso de la primera, uno de los personajes hace sonar un acordeón para indicar que la música es diegética y parte de la historia.

Las tres canciones tienen diferentes funciones. Piraten koplak se escucha con letra en tres ocasiones, mientras que la melodía sola y/o tarareada se escucha en varias más. Inicialmente sirve de introducción a la historia al mismo tiempo que se presenta a un personaje y sus características -Dimitri, el capitán del barco Caín- y el oficio de pirata. También se utiliza como recurso narrativo y funcional de los personajes para que el sonido provoque un desprendimiento en la cueva en la que están secuestrados. Finalmente, la película se cierra con una secuencia en la que la canción toma la función de conclusiva. La canción Perla zuria es un tema de esperanza que se escucha en dos ocasiones. En primer lugar, se presenta como un mensaje oculto del pirata Macaos cantado por un loro mágico que anima a los piratas a hacer frente al esclavista que les amenaza. Esa estrofa se repite más tarde cantada por la hija de Macaos, Loreley, para guiar al navío Caín a través de la tormenta. En esa ocasión la canción es un dúo cantado por padre -el loro- e hija, acompañados del coro que forman los piratas del Caín. Itsas Andere es una canción de despedida cantada por la pirata anciana Ma cuando es sentenciada a muerte. En ella indica que vengará el daño que se ha hecho a su gente. 


\section{LA LEYENDA DEL UNICORNIO: UNA PELÍCULA EN VERSO}

La película La Leyenda del Unicornio es dirigida por Maite Ruiz de Austri ${ }^{5}$ y estrenada en el año 2001. Es un largometraje del género musical que incluye varios números musicales. Esta película es una adaptación del musical homónimo creado por los vallisoletanos Javier Muñoz y Diego Yzola del grupo teatral Jana Producciones. Precisamente Yzola es el encargado de firmar la mayoría de las canciones con letra de la película junto al compositor Jose-Tomas Sousa y el grupo de folk Acetre. La adaptación y traducción al euskera la realiza Jesús Sala.

El guion de la obra teatral está íntegramente escrito en verso, característica que se mantiene en la película. Las canciones son adaptadas al nuevo medio, siendo un total de nueve: El pequeño unicornio, Canción del puerto, Canción de los terrores, Inocencia de Marina, El fondo del mar, Amor de Marina, La canción de la botella, Canción de los niños y Celebraremos ${ }^{6}$. Los estilos musicales son muy diferentes y hay ejemplos de rock, folk, country, reggae, metal o música épica. Todas las canciones son cantadas por los personajes dentro de las diégesis y se corresponden al estilo Broadway, con excepción de El pequeño unicornio, que lo hace con una voz over femenina. Además, cuatro de ellas cuentan con música in interpretada por los personajes, como el anciano que toca el acordeón en Canción del Puerto, la banda de peces de El fondo del mar y Celebramos, o el niño a la guitarra de Canción de los Niños. También se suman efectos de iluminación que simulan una actuación teatral, como el foco que ilumina a la protagonista en Amor de Marina. Cabe destacar que muchas de las canciones son interrumpidas por diálogos, como en el caso de Amor de Marina, donde el diálogo es además parte de la canción.

Respecto a las funciones, El pequeño unicornio y Canción de los terrores presentan a un protagonista y a los antagonistas respectivamente. Canción del puerto explica el trabajo de los adultos y describe su marcha del pueblo. La canción Inocencia de Marina es un monólogo de esperanza en el que la protagonista interpela sin respuesta al Unicornio, al igual que la canción Amor de Marina, canción de amor maternal en la que interpela su madre convertida en estatua.

El Fondo del Mar es una canción cuya representación en imágenes y objetivos dentro de la trama tienen un gran parecido al tema Under the Sea de la película de Walt Disney Company The Little Mermaid (Ron Clements \& John 
Musker, 1989). En ambos casos los peces intentan convencer a la protagonista que debe quedarse bajo el mar. Incluso, el Besugo cantante tiene acento latino. La canción El fondo del mar, a la que se le restan algunos diálogos y se le suma metraje constituye el grueso del cortometraje Marina, la princesa del fondo del mar (Maite Ruiz de Austri, 2001).

Los temas La canción de la botella y Canción de los niños son puramente descriptivos. No aportan novedad a la trama y consideramos que tienen la función de espectáculo. La canción conclusiva, Vamos a celebrar junta a todos los personajes en un gran acto musical final con música diegética. Además, el Besugo interpela a la audiencia para que participe dando palmas al ritmo de la música.

Algunos personajes tienen un leitmotiv que les acompaña, como los acordes épicos del Unicornio adulto -que el pequeño Unicornio toma como suyo al final de la película- o las guitarras eléctricas de los monstruos que aterrorizan a los niños.

La Leyenda del Unicornio se mantiene como una excepción en la filmografía de Ruiz de Austri en lo que se refiere al tratamiento musical; en los largos que le siguen tan solo destaca una canción con letra en Animal Channel (Maite Ruiz de Austri, 2008), que sirve para narrar el viaje que los personajes realizan. Por su parte, Lucius Dumben berebiziko bidaia (Maite Ruiz de Austri, 2011) da relevancia a la música en un gran acto final de celebración. El subtítulo del film, 'Los derechos humanos, tu mejor instrumento', denota la importancia de la música con el doble sentido de la palabra 'instrumento', entendido como herramienta y objeto para producir música. Ese epígrafe es tomado de la campaña a favor de los derechos humanos de la ONG Músicos sin Fronteras. La premisa de la película es la búsqueda de la fuente de la felicidad de la humanidad, resultando en que los derechos humanos, en este caso plasmados a través de la música, son el elemento unificador por excelencia. Los aplausos y golpes rítmicos de los personajes invitan a participar en la melodía, tal y como se hace en el final de La Leyenda del Unicornio. La canción de título Los derechos humanos, tu mejor instrumento es compuesta por Pedro Calero y Mili Vizcaíno. Tanto en castellano como en euskera la canción es interpretada por artistas como Nacho Campillo, Bebe, Cira, Mikel Antero, Iker Bengoetxea, Ane Gabarain o Sure Arakama. 


\section{BARRIOLA, SAN ADRIANGO AZERIA: EL POEMA HECHO MÚSICA}

Barriola, San Adriango Azeria es el quinto largometraje dirigido por el pionero de la animación vasca Juanba Berasategi. Esta película estrenada en 2008 se basa en una novela corta que el escritor y poeta vasco Koldo Izagirre. Esta novela homónima está redactada en prosa e incluye varios poemas. Precisamente esos poemas son los que convertidos en canciones adquieren un relevante papel en la banda sonora de la película. Por ello, esta película es la excepción en la filmografía de Berasategi respecto al uso de la música; en los siete largometrajes que dirige solamente en dos hay una canción cantada, concretamente la ya citada Kalabaza Tripontzia -con palabras apenas audibles- y los títulos de crédito de Ahmed, Alhambrako printzea (Juanba Berasategi, 1998).

La música de la película es compuesta por Joserra Senperena, compositor que trabaja previamente con Berasategi en el largometraje Pailazokeriak y con el que vuelve a coincidir en Nur eta Herensugearen tenplua (Juanba Berasategi, 2017). Senperena también compone la música de Lur eta Amets (Imanol Zinkunegi, Joseba Ponce, 2019) producida por Lotura Films dentro de la agrupación L.A. Ekoizpenak.

Barriola, San Adriango Azeria no es una adaptación exacta de la novela, aunque en muchas ocasiones los diálogos son idénticos. Los ocho poemas de la novela -tres de ellos son el mismo repetido-, se convierten en diez canciones, de las cuales tres son exclusivas de la película.

Las nueve primeras canciones son interpretadas por un narrador omnisciente con música y voz over extradiegética. Los temas tienen función narrativa y acompañan a los personajes cuando se mueven por los caminos y bosques y ambientan las acciones; explican lo que están pasando a los personajes mencionando sus nombres e incluso adelantan lo que va a suceder. Además, en la mayoría de las ocasiones sirven como transición entre secuencias. Por ejemplo, la primera canción presenta al protagonista y sitúa la acción en un entorno geográfico concreto del País Vasco. Teniendo en cuenta las letras de las canciones y el argumento de la película en el que la naturaleza y la civilización se muestran enfrentadas, se puede interpretar que el narrador es la propia naturaleza. Hay que señalar que la melodía cantada en ocasiones se presenta sin letra, nuevamente como transición acompañando a la acción de los personajes. 
La última canción es la única cantada por un personaje de la película, la joven Graziana. La canción es nuevamente over pero dentro de la diégesis; es un monólogo que exalta los sentimientos de la protagonista que parece cantar para sí misma en primera persona. No solo nos cuenta lo que siente, sino que también explica la transformación que ha sufrido el personaje; el desamor ha hecho que deje atrás su inocencia para convertirse en una mujer adulta. La canción cumple principalmente la función conclusiva: el viento se convierte en el hilo conductor de las últimas escenas -hace volar el vestido que simboliza la inocencia de la joven- y nos enseña la situación en la que han quedado el resto de los personajes, coincidiendo con el cambio de estación. Pero, esta canción también puede considerase de despedida, ya que Graciana dice adiós a Barriola, el hombre que ha sido su interés amoroso y al que se muestra por medio de montaje en paralelo. Es precisamente el montaje el que hace que situemos la canción dentro del estilo videoclip. La melodía de esta canción se adelanta en la película cuando las acciones, sin estar protagonizadas por Graziana, tienen relación con ella.

\section{CONCLUSIONES}

El presente artículo nos sirve para reflexionar sobre el uso de la música que hacen los largometrajes de animación producidos en el País Vasco y en concreto tres de esas películas analizadas. Dichos tres films hacen una aproximación muy diferente al género musical.

Entre los tres ejemplos analizados La Leyenda del Unicornio es el único musical puro. El estilo Broadway de sus actos musicales asemeja a los clásicos de The Walt Disney, y todas menos una de las actuaciones lo son dentro de la diégesis. En ocasiones además incluyen elementos de ambientación que no parecen tener razón de ser dentro de la historia, como luces de colores y la interpelación directa al público.

Karramarro Uhartea también podemos considerarlo un musical del estilo Broadway. Sin embargo, la poca cantidad de canciones -solamente tres-, hace que la película no destaque tanto como musical si lo comparamos con La Leyenda del Unicornio. 
Por su parte, Barriola, San Adriango azeria, sin ser un musical hace una interesante adaptación de los poemas de Koldo Izagirre a la animación. De las diez canciones presentes en el film nueve de ellas tienen función descriptiva mientras que la última es más propia de un musical.

Cabe destacar que en las tres películas las canciones cantadas por mujeres tienen especial relevancia. En todos los casos las voces femeninas expresan sus sentimientos a través de la música, como si estuvieran predispuestas a ello.

Además del estudio en profundidad de esos tres largometrajes este texto plantea una reflexión global sobre el resto de la cinematografía vasca de animación. Se identifican algunas funciones que se repiten, como son las canciones conclusivas con un gran acto musical final -presentes en las películas analizadas-, las de introducción o las que se escuchan sobre los créditos finales. Destacan sobre todo las canciones over. Sin embargo, no se impone la fórmula del musical de animación y menos del estilo Broadway. Identificamos una o dos canciones por película, a pesar de encontrar cuidadas bandas sonoras con reputados compositores, bandas u orquestas. Por otro lado, encontramos varios casos en los que la música es parte de la trama.

En este estudio se exponen algunos de esos ejemplos, pero hay muchas otras canciones que no se mencionan y largometrajes que no se han analizado. Por ello, y tomando como base el estudio de Alba Montoya Rubio, es interesante plantear de cara al futuro una investigación de todos los largometrajes o al menos de las obras de autores y/o productoras específicas, con el fin de conocer más en profundidad las características del cine de animación vasco.

\section{Referencias bibliográficas}

Candel Crespo, José María. 1993. Historia del dibujo animado español. Murcia: Filmoteca Regional de Murcia

Cassetti, Francesco \& Federico Di Chio (1991). 2010. Cómo analizar un film. Traducción de Carlos Losilla. Barcelona: Paidós

Junguitu Dronda, Maitane. 2019. "Kalabaza Planeta eta Juanba Berasategi: Panorámica de la animación comercial vasca”. Tesis Univ. del País Vasco. Inédita

Manzanera Molina-Niñirola, María. 1992. Cine de animación en España: Largometrajes 19451985. Murcia: Universidad de Murcia 
Martínez Barnuevo, María Luisa. 2008. El largometraje de animación español: análisis y evaluación. Madrid: Fundación Autor

Montoya Rubio, Alba. 2017a. "Entre Broadway y el videoclip: Los números musicales de las películas animadas de los estudios Walt Disney". En Música y medios audiovisuales: Análisis, investigación y nuevas propuestas didácticas, vol. 1, Julio Arce, Teresa Fraile, eds., 363-76. Alicante: Letra de Palo

Montoya Rubio, Alba. 2017b. "Les pel·lícules musicals d'animació dels estudis Walt Disney: Anàlisi de l'aparició i evolució dels elements recurrents a les cançons (1937-2010)". Tesis Univ. de Barcelona. Inédita

Ramos Machí, María José. 2012. "El primer largometraje de animación europeo en color: Garbancito de la Mancha (1945); Análisis de la música de Jacinto Guerrero". Anuario Musical 67: 223-70. https://doi.org/10.3989/anuariomusical.2012.67.143

Román Gubern Garriga-Nogues, et al. 2017. Historia del cine español. Madrid: Cátedra

Solomon, Stanley J. 1976. Beyond formula: American film genres. New York: Harcourt Brace Jovanovich

Thomas, Bob. 1968. Maravillas de los dibujos animados. A cargo... del Estudio de Walt Disney; traducción, Juan Blanco Catalá. Valencia: Gaisa

\section{Notas}

${ }^{1}$ Los títulos de las películas utilizados en el artículo se corresponden con los de la versión original de las mismas, según recogemos en la tesis doctoral Kalabaza Planeta eta Juanba Berasategi. Panorámica de la animación comercial vasca (Junguitu Dronda 2019). Sus traducciones son La Isla del Cangrejo, Adabarkar Txikiaren Kondaira y El Zorro Ladrón. En las citas optamos por mantener el título elegido por los autores a la hora de nombrar dichas películas.

${ }^{2}$ Tomamos como base para la teoría del sonido el trabajo de Casetti y Di Chio, que determinan varias categorías según la colocación del mismo, por ejemplo especificando si la fuente es o no diegética y si está o no encuadrada dentro dde la imagen (Casseti \& Di Chio [1991] 2010).

${ }^{3}$ Txirri Mirri y Txiribiton son un conocido trío de payasos que comenzaron a actuar a principios de los años setenta. Sus actuaciones, íntegramente en euskera y realizadas tanto en teatro como en programas de televisión incluyen numerosas canciones. Previamente al largometraje son protagonistas del corto Tortolika eta tronbon (Txabi Basterretxea, Joxean Muñoz, 1998) en el que la música tiene también especial relevancia en la trama. Cabe destacar que Joxean Muñoz es guionista y letrista de la película analizada Karramarro Uhartea.

${ }^{4}$ Descartamos el análisis de Betizu Izar artean en el estudio, ya que aunque presenta varios números musicales, la saga Betizu forma parte del programa infantil homónimo para la televisión pública vasca. No obstante, de cara a futuras investigaciones se plantea un estudio de la trilogía.

${ }^{5}$ Son varias las películas que Maite Ruiz de Austri produce con la empresa EXTRA Extremadura de Audiovisuales en Extremadura. No obstante, debido al origen vasco de la directora, así como a la participación de entre otros el estudio Dibulitoon, sus obras las consideramos como parte de la filmografía vasca 
${ }^{6}$ Los títulos de las canciones son los que se muestran en los créditos de la película. Estos títulos difieren de los presentados en la compilación de canciones del musical realizada Jana Producciones. Además, la película incluye una canción más. 